\title{
The influence of heart failure on longitudinal changes in cognition amond individuals 80 years of age and older
}

Carina Hjelm, A Dahl, Anders Broström, J Mårtensson, B Johansson and Anna Strömberg

\section{Linköping University Post Print}

N.B.: When citing this work, cite the original article.

This is the authors' version of the following article:

Carina Hjelm, A Dahl, Anders Broström, J Mårtensson, B Johansson and Anna Strömberg, The influence of heart failure on longitudinal changes in cognition amond individuals 80 years of age and older, 2011, Journal of Clinical Nursing, 21(7-8), 994-1003.

which has been published in final form at:

http://dx.doi.org/10.1111/j.1365-2702.2011.03817.x

Copyright: Blackwell Publishing http://www.blackwellpublishing.com/

Postprint available at: Linköping University Electronic Press http://urn.kb.se/resolve?urn=urn:nbn:se:liu:diva-74495 


\section{The influence of heart failure on longitudinal changes in cognition among individuals 80 years of age and older}

Carina Hjelm, Anna Dahl, Anders Broström, Jan Mårtensson, Boo Johansson, Anna

Strömberg

\section{Authors:}

Carina Hjelm,RN, PhD student, Department of Medical and Health Sciences, Division of Nursing Science, Linköping University, Department of Cardiothoracic Surgery, Linköping University Hospital ; Anna Dahl, PhD in Gerontology, Researcher, Institute of Gerontology, School of Health Sciences, Jönköping University ; Anders Broström, RN, Associate Professor , Department of Medical and Health Sciences, Division of Nursing Science, Department of Clinical Neurophysiology, Linköping University Hospital, Department of Nursing Science, School of Health Sciences, Jönköping University; Jan Mårtensson, RN, Associate Professor, Unit of Research and Development in Primary Care, Jönköping , Department of Nursing Science, School of Health Sciences, Jönköping University; Boo Johansson, Professor of Geropsychology, Department of Psychology, University of Gothenburg Sweden; Anna Strömberg, RN, Professor, Department of Medical and Health Sciences, Division of Nursing Science, Linköping University, Department of Cardiology, Linköping University Hospital, Sweden

Corresponding author: Carina Hjelm, Department of Medical and Health Sciences, Division of Nursing Science, Linköping University, S-581 85 Linköping, SWEDEN.

Telephone. +46-10-1031787. E-mail: carina.hjelm@liu.se

\section{Contributions}


Study design: CH, AD, A.S, B.J, JM, data collection and analysis: CH, A.D, A.S and manuscript preparation: CH, A.D, A.S, A.B, JM, BJ

Conflict of interest: There is no conflict of interest to declare

\section{Acknowledgement}

Health Research Council in the South-East of Sweden and the Faculty of Health Science at Linköping University provided financial support. The OCTO-Twin data collection was supported by a grant from the US National Institute on Aging of the National Institutes of Health (NIA:AG 08861), The Swedish Council for Working Life and Social Research, The Adlerbertska Foundation, The Hjalmar Svensson Foundation, The Knut and Alice Wallenberg Foundation, The Wennergren Foundations, and The Wilhelm and Martina Lundgrens Foundation, Department of Medical Epidemiology and Biostatistics, Karolinska Institute, Stockholm, Institute of Gerontology, School of Health Sciences, Jönköping. 
Keywords: chronic heart failure, cognitive dysfunction, episodic memory, heart failure, neuropsychological testing, octogenarians, self-care, spatial abilities,

\begin{abstract}
Aim: The aim of this study was to examine the relationship between HF and specific cognitive abilities in octogenarians with regard to level and change over time.
\end{abstract}

Background: Cognitive impairment is influenced by a multitude of factors and the impact of heart failure (HF) is debated. Intact cognitive ability is crucial for successful self-care in HF patients. Middle aged patients with HF seem to have an increased risk of cognitive impairment. No studies have examined the association between HF and longitudinal cognitive changes in octogenarians (individuals 80 years and older).

Design: A prospective longitudinal design.

Methods: Cognitive tests were carried out on five occasions (1991-2002) in 702 octogenarians from the Swedish Twin Registry, including same sex twin pairs. The testbattery included measurement of processing speed, visuospatial ability, short term, episodic and semantic memory. Latent growth curve modelling was employed to measure change and performance over time and compares the group diagnosed with HF to individuals without a HF diagnosis.

Results: At baseline the participants' mean age was 83.5 years, $67 \%$ were female and $13 \%$ suffered from HF. Individuals diagnosed with HF scored significantly lower in spatial abilities and episodic memory than participants not diagnosed with HF. Moreover measures of episodic memory declined more over time in individuals diagnosed with HF. There were no significant differences between the groups in other cognitive tests.

Conclusion: Spatial problems and episodic memory have implications for everyday life. This might contribute to decreased adherence to prescribed therapy and self-care management and lead to socio-behavioural problems due to an impaired capacity to drive, read and write. 
Relevance for clinical practice: Nurses should take to account in their assessment that cognitive impairment may restrain elderly HF patient's ability to make decisions and perform self-care actions. Patient education strategies should also be adapted to cognitive ability.

\section{Introduction}

Approximately 15 million people suffer from heart failure (HF) in Europe. The prevalence of HF is $10-20 \%$ among those above 80 years of age and the HF syndrome is associated with an elevated mortality risk, morbidity, and decreased quality of life (Dickstein et al. 2008).

Pharmacological therapy together with self-care management are the most important parts of successful HF treatment. Self-care can be defined as a naturalistic decision-making process used by patients to maintain their health (Carlson et al. 2001). It include actions aimed at maintaining physical stability and avoidance of behavior that can worsen the condition (Dickson et al. 2007). A successful self-care can significantly impact on functional capacity, well-being, morbidity, and prognosis (Dickstein et al. 2008, Lindenfeld J. 2010). However, elderly patients with HF commonly fail to recognize early symptoms of deterioration and are unaware of their increasing severity (Carlson et al. 2001). It is therefore especially important to help these elderly patients with somatic awareness and interpretation of symptoms (Riegel et al. 2010). Cognitive impairment is important to screen for since it influence HF patients' abilities to perform self-care management e.g. make lifestyle changes, adhere to medical treatment and monitor, evaluate and treat symptoms of deterioration (Stromberg et al. 2006). Symptomatic HF patients who practice self-care have a better event- free survival (Lee et al. 2010, Stromberg et al. 2003).

Patients with HF have a reduced cerebral blood flow, altered brain metabolism and structural brain pathology including reduced grey matter volume and white matter lesions (Almeida $e t$ al. 2005, Alves et al. 2005, Woo et al. 2003), which may lead to cognitive dysfunction (Cacciatore et al. 1998, Saxena \& Schoemaker 1993). A meta-analysis including 18,000 people mainly from cross-sectional or case control studies, showed that those diagnosed with 
HF had a $62 \%$ higher risk of cognitive impairment compared with those without HF (Vogels et al. 2007). In these studies the samples have been younger than the average HF patients (Cohen \& Mather 2007, Vogels et al. 2007). Middle aged patients with HF seem to have an increased risk of cognitive impairment. To our knowledge no previous longitudinal study has examined the relationship between $\mathrm{HF}$ and cognitive functioning in octogenarians

(individuals 80 years and older). The aim of this study was to examine the relationship between $\mathrm{HF}$ and specific cognitive abilities in octogenarians with regard to level and change over time.

\section{Methods}

The population-based sample consisted of participants from the Octogenarian Twin (OCTOtwin) study designed to investigate bio-behavioural functioning among the oldest-old population (Cederlof \& Lorich 1978). A prospective longitudinal design was used including five measurement occasions with two-year intervals. The study included same-sex twin pairs born in 1913 or earlier where both individuals accepted participation. The drop-out rates and selection criteria have previously been described (McClearn et al. 1997). In total, 702 individuals aged 80 and older were included in this study. The OCTO-twin study was approved by the Regional Ethical Review Board in Stockholm, Sweden.

\section{Data collection and measurements}

Information about diseases, medications and health problems was collected through medical records, drug prescriptions and self-reports. Cognitive and physical abilities were assessed 5 times during a 10-year period, between 1991 and 2001 in the participants`own home by trained research nurses. The in-person testing (IPT) 1-5 (Table 1) session took on average 3.5 hours and included rest periods. All types of dementia (unclassified, mixed, secondary dementia, Alzheimer disease, vascular dementia) were diagnosed according to the Diagnostic and Statistical manual of Mental Disorder (DSM IIIR criteria) (American Psychiatric Association 1987). Individuals suspected to suffer from dementia were diagnosed at a 
consensus diagnosis conference. All available information was used in the diagnostic procedure, such as review of medical records, the IPT protocols including information from the cognitive tests and an interview about memory and cognitive problems (Pedersen et al. 2004). Other clinical diagnoses such as obstructive lung disease, angina pectoris, myocardial infarction, stroke, HF, were derived from medical records starting from 1980 and reviewed by an experienced physician (ICD-10 1992, Nilsson et al. 2002). A second independent review of the medical records was conducted by the first author $(\mathrm{CH})$, to ensure validity and year of the HF diagnosis.

\section{Cognitive test}

Processing Speed (Dureman \& Sälde 1959, Wechsler 1991) was measured by following: (1) Symbol Digit Test, a modified version of the Wechsler Adult Intelligence scale-revised. The test requires a verbal response of the appropriate digit that matches a printed symbol. The score is the sum of the correct numbers of symbol digits in two 45 -second trials.

(2) Perceptual Speed is a timed picture (figural similarity) matching task. The participant is asked to detect one item among five alternatives identical to the target item presented. Visospatial ability (Dureman \& Sälde 1959) was measured by Koh`s Block Design test. The participant is presented with red and white blocks and cards with different patterns. The participants have to reproduce seven patterns with the blocks as quickly as possible.

Short term memory (Wechsler 1991) was measured by Digit Span. The participant has to repeat a sequence of numbers in the same order as previously presented (Digit span forward). In Digit span-backward test, digits have to be repeated in reverse order.

Episodic memory (Johansson 1998/89, Thurstone \& Thurstone 1949, Wechsler 1991) was measured by: (1) Prose Recall test (Swedish version of the Logical Memory in the Wechsler memory Scale) where the participants are asked to immediately recall a brief story of 100 words and the results are coded for the amount of information recalled. (2) Thurstone's Picture Memory test which is a non-verbal memory test. Participants are shown 28 drawings 
and then asked to point them out among other drawings. (3) Memory-in-Reality (MIR) test is a delayed (30 $\mathrm{min})$ free recall test of 10 objects.

Semantic memory (Dureman \& Sälde 1959, Johnsson \& Molander 1964) was assessed by 2 tests: (1) The Swedish version of the information task with 22 general knowledge questions. (2) Verbal Meaning test where participants are asked to identify a synonym to a target word, the test consists of two parts of 15 words each.

\section{Statistical analysis}

Group data (HF and non-HF) are presented as median (range/quartiles), mean, standard deviation (SD) or proportions (\%). Differences between the groups were analysed using independent samples $t$ test and Chi-squared test. To allow comparison across cognitive tests and individuals with and without HF, all scores were standardised into $t$-score (mean=50, $\mathrm{SD}=10$ ) (Streiner \& Norman 2008). Statistical analyses were performed using SPSS version 16.0 (SPSS Inc., Chicago, IL, USA); $p<0.05$ was considered statistically significant based on two- tailed tests. Multilevel models were performed using SAS Proc Mixed multilevel modelling (SAS Institute Inc., Cary, NC, USA). Latent growth curve modelling was employed to explore the potential effect of HF on cognitive performance over time. Latent growth curve models allow comparisons between individual trajectories as well as an average trajectory of decline across the entire sample. Individual changes are assumed to follow the mean path of change for the total population, but the random effects allow individual levels of function to be higher or lower and the rate of decline or growth to be faster or slower (SAS Institute Inc) . A full maximum-likelihood estimate (MLE) technique was used in the growth models (McArdle et al. 2002, McArdle \& Nesselroade 2003). Both linear and quadratic (curve linear) models were considered. As independence in twin pairs could not be assumed, models were adjusted to account for the correlation within twin pairs. Analysis with no covariates included was first performed (model 1). Model 2 controlled for: sex, age, educational level, diabetes, and model 3 for sex, age, educational level, diabetes, arterial hypertension, and smoking. The covariates in model 2 were chosen because they have been 
found to influence cognitive abilities and the risk of developing dementia (Qiu et al. 2007). All analyses were carried out twice: first including all individuals with dementia and secondly excluding them. In the initial analyses all individuals who suffered from HF at baseline/ITP 1 or developed HF during ITP 2-4 were included in the HF group. It was assumed that the majority of the individuals diagnosed with HF during IPT 2-4 had developed HF already at study inclusion. The rationale for this was that HF, especially in the elderly, often develops gradually during a long period of time. To assure that HF was diagnosed at subsequent IPTs, analyses were also performed with all neuropsychological data excluded until the HF diagnosis was documented in the medical records.

\section{Results}

\section{Demographic and clinical characteristics}

Out of 702 participants included in the study, 95 had HF at baseline (IPT 1) (1991-1993) and another 96 developed HF between IPT 1-4. Mortality from IPT 1-5 was in total 129 in the HF group. Table 1 shows the total number of individuals with HF at each IPT, new HF cases and participants with HF who had died at each IPT.

Characteristics of participants are presented in Table 2. There were no significant differences between HF and non-HF individuals in vision diseases or hearing problems.

Insert Table 1- 2 here

\section{Cognitive measurements}

Individuals diagnosed with HF demonstrated lower performance in almost all cognitive tests (Table 3). Significant differences between the groups were seen in IPT 1-3 in Block Design, Digit Span backward and forward, Thurstone's Picture, Prose Recall and MIR, no differences were seen between the groups in IPT 4-5 (Table 3).

There was a significantly higher drop-out rate (between 4-20\%) among individuals with HF in IPT 1-3 in five tests (Block Design, Digit Span backward and forward, Thurstone's Picture, 
Prose Recall and MIR). The level of missing data increased in both groups during follow-up, in IPT 4-5, there were no significant differences regarding missing data.

Insert Table 3 here

The findings based on the longitudinal observations showed that participants with HF demonstrated a significantly lower mean performance level in the Block Design test measuring spatial ability in model 1 including dementia $(\mathrm{p}=0.0446)$ as well as when excluding dementia cases $(\mathrm{p}=0.0012)$ (Table 4 and 5). Participants with HF performed significantly lower in spatial ability in mean performance when sex, age, education, and diabetes was controlled for in model 2 (Fig. 1) and when controlling for sex, age, education, diabetes, arterial hypertension and smoking in model 3 when those diagnosed with dementia were excluded (Table 5).

In the other cognitive tests there were no significant differences of mean level for individuals diagnosed with HF either with dementia cases included or excluded.

Analyses of change trajectories across cognitive tests and between the groups (Table 4) revealed that individuals with HF declined more in episodic memory (Prose Recall and Thurstone Picture Memory) with dementia cases included (model 1). In model 2 and 3, performance in the episodic memory tests (Prose Recall) showed a longitudinal decline in the HF group when including dementia. Prose Recall have a longitudinal decline in model 1, 2, 3 and Thurstone Picture in model 2, when excluding individuals diagnosed with dementia among the HF participants (Table 5; Figs 2 and 3).Short term memory (Digit Span forward) declined significantly more over time in model 2 and 3 in individuals with HF and dementia cases included (Table 4 and Fig. 4).

Insert Table 4-5 and Figure 1-4 here 
When cognitive data were excluded for individuals who had developed HF at subsequent IPT sessions ( $n=96)$, there were no significant differences between the groups, with or without dementia, in their change trajectories for any of the neuropsychological tests examined by models 1-3.

\section{Discussion}

\section{Result discussion}

The aim of this study was to examine the relationship between HF and level and change trajectories in a set of specific cognitive tests in a population-based, longitudinal sample of individuals aged 80 and older. Our main finding was that HF was significantly associated with decline in episodic memory and spatial performance. Visuospatial abilities are used to control movement guidance of limb and body movements (Graziano \& Gross 1998) and are fundamental functions for more complex activities such as driving, reading and writing (Luria 1970). A decreased spatial ability may also negatively influence the ability to understand, interpret and adhere to a complex medical treatment. Episodic memory handles autobiographical events, such as acquisition and retrieval of information which is related to time and place (Tulving 1985). An interpretation could be that when these cognitive abilities are impaired in patients with $\mathrm{HF}$, they might have problems remembering daily medications and self-care management which involves decision-making to monitor, evaluate and take actions to ameliorate symptoms when they occur (Dickstein et al. 2008, Lindenfeld J. 2010). The results regarding episodic memory were somewhat inconclusive. There seem to be a better performance in IPT 4 and 5 in semantic memory and episodic memory among the patients with HF (Table 3). A possible explanation could be that since HF has such poor prognosis, those individuals surviving are probably healthier and more cognitively alert despite the age and dementia factor. Our finding that HF patients decline more over time with regards to of episodic memory was not confirmed when individuals who developed HF during the course of the study were excluded. However, it can be argued that this might be a too rigid 
way of defining individuals with HF because HF typically develops gradually over a long time, especially in the elderly. It is likely that individuals who had developed HF on subsequent occasions were in fact affected already at study inclusion.

The longitudinal performance differed in Prose Recall and Thurstone Picture and in Digit Span forward tests, especially when dementia cases were included. This finding might be explained by the fact that episodic memory is affected early in the course of dementia and therefore it becomes more obvious when dementia cases were included.

Several studies evaluating cognitive function in HF have been performed (Pressler 2008, Stanek et al. 2009, Vogels et al. 2007). However, the results are difficult to summarise since different tests measuring cognitive ability have been used. Previous research has shown that, memory, language, processing speed, attention and general cognitive deficits appear to be the most affected cognitive domains in patients with HF compared to those in healthy controls (Vogels et al. 2007). Singh-Manoux and colleagues found changes in several cognitive abilities in middle-age patients with a history of coronary heart diseases when controlling for covariates similar to those used in our study (Singh-Manoux et al. 2008). It is questionable if the same conclusions can be drawn for the oldest-old because most studies have investigated younger or mixed age groups. More studies, especially in older patients, are needed before firm conclusions can be drawn about the cognitive domains that are affected over time by HF. Despite inconclusive results about affected domains, there is a growing body of evidence showing that HF has detrimental effects on cognitive abilities and that memory dysfunction can be a predictor for mortality. Unfortunately, information and education about HF and selfcare is usually not alert to these changes (Riegel et al. 2010). Hence, it is important for healthcare providers to screen for cognitive impairments before it comes evident. 
A strength of this study is that it is a population based prospective longitudinal design with individuals aged 80 and older, and another strength is that we used an extensive battery of neuropsychological tests. Few of the studies had a longitudinal design. Furthermore, most studies have not controlled for other influencing factors assumed to affect the relationship between HF and cognition.

The amount of missing data in the cognitive tests was greater among the individuals diagnosed with HF in IPT 1-3 in the test measuring spatial ability and episodic memory. This might be explained by the fact that the HF population was more fatigued or that a greater proportion of HF patients were too cognitively impaired to actually be able to perform the tests. In general, the differences in cognitive performance were more substantial between individuals diagnosed with HF and without HF in the early assessments. An explanation for this could be that in the later IPT there were fewer participants due to death and missing data, which decreased the possibility to detect significant differences. If this is the case, this might indicate that the negative effect of HF on these abilities (spatial ability and episodic memory) is even larger than actually observed in this study. Those among the oldest-old who have survived despite suffering from HF among the oldest -old may have had a milder form of HF and the effects on cognitive functioning are therefore smaller. Those with complete data in all IPT, influence the growth curve model analyses more than those with missing data. Our study has several limitations, data collection was performed between 1991-2001 and there has been a substantial progress in diagnostic methods and medical treatment in the last decade. The pharmacological treatment in the HF group was not in accordance with present treatment recommendations (Dickstein et al. 2008). It would therefore be interesting to further study the effects of HF on cognition in an elderly sample receiving modern HF therapy. Another limitation is that the medical diagnosis of HF was derived from medical records and not based on a standardized clinical evaluation procedure. HF is often both over-and underdiagnosed in the elderly (Dickstein et al. 2008). Notably, our HF individuals were not treated with modern HF therapy that lowers blood pressure and they had fairly high blood pressures 
at baseline. Improved blood pressure control seems to be an important contributor to cognitive improvement (Stanek et al. 2009).

\section{Conclusion}

The results from this study may be used to effectively recognise the occurrence and severity of cognitive impairment in patients with HF and its effects on self-care management.

\section{Relevance for clinical practice}

HF is associated with a lower performance in visuospatial ability and episodic memory. Impaired visuospatial ability and episodic memory are crucial in coping with everyday life and may contribute to several problems, for example a deteriorated ability to drive, read and follow prescribed medical therapy. It is important to screen for cognitive impairment since it influence HF patients abilities to perform a successful self-care management. 


\section{References}

Almeida JR, Alves TC, Wajngarten M, Rays J, Castro CC, Cordeiro Q, Telles RM, Fraguas RJ \& Busatto GF (2005): Late-life depression, heart failure and frontal white matter hyperintensity: a structural magnetic resonance imaging study. Braz J Med Biol Res 38, 431-436.

Alves TC, Rays J, Fraguas R, Jr., Wajngarten M, Meneghetti JC, Prando S \& Busatto GF (2005): Localized cerebral blood flow reductions in patients with heart failure: a study using 99mTc-HMPAO SPECT. J Neuroimaging 15, 150-156.

American Psychiatric Association (1987) Diagnostic and statistical manual of mental disorders, Rev. 3rd. edn, Washington, DC: Author.

Cacciatore F, Abete P, Ferrara N, Calabrese C, Napoli C, Maggi S, Varricchio M \& Rengo F (1998): Congestive heart failure and cognitive impairment in an older population. Osservatorio Geriatrico Campano Study Group. J Am Geriatr Soc 46, 1343-1348.

Carlson B, Riegel B \& Moser DK (2001): Self-care abilities of patients with heart failure. Heart Lung 30, 351-359.

Cederlof R \& Lorich U (1978): The Swedish Twin Registry. Prog Clin Biol Res 24 Pt B, 189195.

Cohen MB \& Mather PJ (2007): A review of the association between congestive heart failure and cognitive impairment. Am J Geriatr Cardiol 16, 171-174.

Dickson VV, Tkacs N \& Riegel B (2007): Cognitive influences on self-care decision making in persons with heart failure. Am Heart J 154, 424-431.

Dickstein K, Cohen-Solal A, Filippatos G, McMurray JJ, Ponikowski P, Poole-Wilson PA, Stromberg A, van Veldhuisen DJ, Atar D, Hoes AW, Keren A, Mebazaa A, Nieminen M, Priori SG \& Swedberg K (2008): ESC guidelines for the diagnosis and treatment of acute and chronic heart failure 2008. Eur J Heart Fail 10, 933-989.

Dureman I \& Sälde H (1959) Psykometrisk och Experimental-Psykologiska metoder för klinisk Tillämpning (Psychometric and Experimental-Psychological methods for Clinical Application). Almqvist \& Wiksell, Uppsala, Sweden.

Graziano MS \& Gross CG (1998): Spatial maps for the control of movement. Curr Opin Neurobiol 8, 195-201.

ICD-10 (1992) International Statistical Classification of diseases and Health problems. World Health Organisation, Geneva.

Johansson B (1998/89) The MIR-Memory in Reality Test. Psykologiförlaget AB, Stockholm.

Johnsson C-O \& Molander L (1964) Manual of the CVB-scales. Psykologi förlaget AB, Stockholm.

Lee CS, Moser DK, Lennie TA \& Riegel B (2010): Event-free survival in adults with heart failure who engage in self-care management. Heart Lung.

Lindenfeld J. AN, Boehmer J P., Collins Sp., Ezekowitz JA., Givertz MM., Klapholz M., Moser DK., Rogers JG., Starling RC., Stevensson WG., Tang WHW., Teerlink JR., Walsh MN. (2010): Executive Summary : HFSA 2010 Comprehensive Heart Failure Practice Guideline. J Card Fail 16, 475-539.

Luria AR (1970) Higher cortical functions in man., New York.

McArdle JJ, Ferrer-Caja E, Hamagami F \& Woodcock RW (2002): Comparative longitudinal structural analyses of the growth and decline of multiple intellectual abilities over the life span. Dev Psychol 38, 115-142.

McArdle JJ \& Nesselroade JR (2003) Growth curve analysis in contemporary psychological research. In Comprehensive handbook of psychology (Schinka J \& Velicer W eds.). Wiley, New York, pp. 447-480.

McClearn GE, Johansson B, Berg S, Pedersen NL, Ahern F, Petrill SA \& Plomin R (1997): Substantial genetic influence on cognitive abilities in twins 80 or more years old. Science 276, 1560-1563. 
Nilsson SE, Johansson B, Berg S, Karlsson D \& McClearn GE (2002): A comparison of diagnosis capture from medical records, self-reports, and drug registrations: a study in individuals 80 years and older. Aging Clin Exp Res 14, 178-184.

Pedersen NL, Gatz M, Berg S \& Johansson B (2004): How heritable is Alzheimer's disease late in life? Findings from Swedish twins. Ann Neurol 55, 180-185.

Pressler SJ (2008): Cognitive functioning and chronic heart failure: a review of the literature (2002-July 2007). J Cardiovasc Nurs 23, 239-249.

Qiu C, De Ronchi D \& Fratiglioni L (2007): The epidemiology of the dementias: an update. Curr Opin Psychiatry 20, 380-385.

Riegel B, Dickson VV, Cameron J, Johnson JC, Bunker S, Page K \& Worrall-Carter L (2010): Symptom recognition in elders with heart failure. J Nurs Scholarsh 42, 92100.

SAS Institute Inc (2002-2003) SAS system for Microsoft Windows, 9.1 edn. SAS Institute Inc.

Saxena PR \& Schoemaker RG (1993): Organ blood flow protection in hypertension and congestive heart failure. Am J Med 94, 4S-12S.

Singh-Manoux A, Sabia S, Lajnef M, Ferrie JE, Nabi H, Britton AR, Marmot MG \& Shipley MJ (2008): History of coronary heart disease and cognitive performance in midlife: the Whitehall II study. Eur Heart $J$.

Stanek KM, Gunstad J, Paul RH, Poppas A, Jefferson AL, Sweet LH, Hoth KF, Haley AP, Forman DE \& Cohen RA (2009): Longitudinal cognitive performance in older adults with cardiovascular disease: evidence for improvement in heart failure. $J$ Cardiovasc Nurs 24, 192-197.

Stromberg A, Dahlstrom U \& Fridlund B (2006): Computer-based education for patients with chronic heart failure. A randomised, controlled, multicentre trial of the effects on knowledge, compliance and quality of life. Patient Educ Couns 64, 128-135.

Stromberg A, Martensson J, Fridlund B, Levin LA, Karlsson JE \& Dahlstrom U (2003): Nurse-led heart failure clinics improve survival and self-care behaviour in patients with heart failure: results from a prospective, randomised trial. Eur Heart J 24, 10141023.

Thurstone LL \& Thurstone TG (1949) Manual to SRA primary mental abilities. . Science Research Associates, Chicago.

Tulving E (1985): How many memory systems are there? American Psychologist 40, 385398.

Wechsler D (1991) Manual for the Wechsler Adult Intelligence Scale Revised. The Psychological Corporation, New York.

Vogels RL, Scheltens P, Schroeder-Tanka JM \& Weinstein HC (2007): Cognitive impairment in heart failure: a systematic review of the literature. Eur J Heart Fail 9, 440-449.

Woo MA, Macey PM, Fonarow GC, Hamilton MA \& Harper RM (2003): Regional brain gray matter loss in heart failure. J Appl Physiol 95, 677-684. 
Table 1 Individuals diagnosed with heart failure (HF) at each in-person testing wave (IPT).

\begin{tabular}{llllll}
\hline & $\begin{array}{l}\text { IPT1 } \\
\mathbf{1 9 9 1 - 1 9 9 3} \\
\mathrm{n}=702\end{array}$ & $\begin{array}{l}\text { IPT2 } \\
\mathbf{1 9 9 3 - 1 9 9 5} \\
\mathrm{n}=702\end{array}$ & $\begin{array}{l}\text { IPT3 } \\
\mathbf{1 9 9 5 - 1 9 9 7} \\
\mathrm{n}=702\end{array}$ & $\begin{array}{l}\text { IPT4 } \\
\mathbf{1 9 9 7 - 1 9 9 9} \\
\mathrm{n}=702\end{array}$ & $\begin{array}{l}\text { IPT5 } \\
\mathbf{1 9 9 9 - 2 0 0 1} \\
\mathrm{n}=702\end{array}$ \\
\hline $\begin{array}{l}\text { HF } \\
\text { (accumulated deaths) }\end{array}$ & 95 & $129(9)$ & $147(45)$ & $112(83)$ & $66(129)$ \\
$\begin{array}{l}\text { Non-HF(accumulated } \\
\text { deaths) }\end{array}$ & 511 & $491(20)$ & $428(79)$ & $357(150)$ & $301(206)$ \\
\begin{tabular}{l} 
Latent HF \\
\hline
\end{tabular} & 96 & 53 & 3 & & 0 \\
\hline
\end{tabular}


Table 2 Sample characteristics at baseline for individuals with and without heart failure (HF).

\begin{tabular}{|c|c|c|c|c|}
\hline & & $\begin{array}{l}\text { HF } \\
n=95\end{array}$ & $\begin{array}{l}\text { Non-HF } \\
\mathrm{n}=607\end{array}$ & p-value \\
\hline Age & mean (SD) & $84.34( \pm 4.05)$ & $83.3( \pm 2.92)$ & $0.266^{\mathrm{a}}$ \\
\hline Female & $\mathrm{n} / \%$ & $64 / 67 \%$ & $404 / 67 \%$ & $0.308^{\mathbf{b}}$ \\
\hline BMI & mean $(\mathrm{SD})$ & $24.02( \pm 4.22)$ & $24.54( \pm 3.74)$ & $0.310^{\mathrm{a}}$ \\
\hline Smoker & $\mathrm{n} / \%$ & $29 / 30 \%$ & $207 / 34 \%$ & $0.493^{\mathbf{b}}$ \\
\hline Education & 1 years mean $(\mathrm{SD})$ & $6.74( \pm 2.2)$ & $7.17( \pm 2.3)$ & $0.004^{\mathbf{b}}$ \\
\hline Blood pre & sure (mmHg) & & & \\
\hline Systolic $\mathrm{r}$ & umbent mean (SD) & $152.04( \pm 21.2)$ & $160.30( \pm 22.9)$ & $0.003^{\mathrm{a}}$ \\
\hline Diastolic & cumbent mean (SD) & $80.86( \pm 12.0)$ & $83.60( \pm 11.8)$ & $0.059^{\mathrm{a}}$ \\
\hline Co-morb & lities & & & \\
\hline All types & diabetes, $\mathrm{n} / \%$ & $23 / 24$ & $99 / 16$ & $0.059^{\mathbf{b}}$ \\
\hline Obstructi & lung disease, $\mathrm{n} / \%$ & $15 / 16$ & $69 / 11$ & $0.217^{\mathbf{b}}$ \\
\hline Angina $\mathrm{Pe}$ & toris, $\mathrm{n} / \%$ & $33 / 35$ & $109 / 18$ & $<0.001^{\mathbf{b}}$ \\
\hline Myocardi & infarction, $\mathrm{n} / \%$ & $28 / 29$ & $119 / 20$ & $0.028^{\mathbf{b}}$ \\
\hline Stroke, $\mathrm{n} /$ & & $33 / 35$ & $133 / 22$ & $0.006^{\mathbf{b}}$ \\
\hline Depressio & $\mathrm{n} / \%$ & $12 / 13$ & $61 / 10$ & $0.443^{\mathbf{b}}$ \\
\hline All types & f dementia, $\mathrm{n} / \%$ & $37 / 38$ & $188 / 30$ & $0.122^{\mathbf{b}}$ \\
\hline Alzheime & disease, $\mathrm{n} / \%$ & $16 / 17$ & $111 / 18$ & $0.734^{\mathbf{b}}$ \\
\hline Vascular & ementia, $n / \%$ & $15 / 16$ & $42 / 7$ & $0.003^{\mathbf{b}}$ \\
\hline Blood sar & ple results & & & \\
\hline Creatinine & mean $(\mathrm{SD})$ & $88.55( \pm 26.53)$ & $78.67( \pm 27.37)$ & $0.024^{\mathrm{a}}$ \\
\hline Urea & mean (SD) & $8.98( \pm 3.25)$ & $7.69( \pm 2.46)$ & $<0.001^{\mathrm{a}}$ \\
\hline Medicatic & & & & \\
\hline Furosemic & $\mathrm{n} / \%$ & $57 / 60$ & $98 / 16$ & $<0.001^{\mathbf{b}}$ \\
\hline Diuretic $n$ & furosemid, n/\% & $25 / 26$ & $69 / 11$ & $<0.001^{b}$ \\
\hline Betablock & $\mathrm{r}, \mathrm{n} / \%$ & $14 / 12$ & $54 / 11$ & $0.811^{\mathbf{b}}$ \\
\hline Calcium-a & tagonist, $\mathrm{n} / \%$ & $2 / 1.7$ & $16 / 3.2$ & $0.406^{\mathbf{b}}$ \\
\hline ACE-Inhi & itor, $\mathrm{n} / \%$ & $5 / 5.3$ & $14 / 2.3$ & $0.099^{b}$ \\
\hline
\end{tabular}

a Independent sample $t$ test

b Chi-squared Pearson 
Table 3. Comparisons between the heart failure (HF) and no heart failure groups (non- HF) in the various cognitive tests. In-Person Testing (IPT ) $1-5$ using t-score, mean $=50$ and $\mathrm{SD}=10$.

\begin{tabular}{|c|c|c|c|c|c|c|c|c|c|c|c|c|c|c|c|c|}
\hline & & \multicolumn{3}{|l|}{ IPT 1} & \multicolumn{3}{|l|}{ IPT 2} & \multicolumn{3}{|l|}{ IPT 3} & \multicolumn{3}{|l|}{ IPT 4} & \multicolumn{3}{|l|}{ IPT 5} \\
\hline & & $\begin{array}{l}\text { Non- } \\
\text { HF } \\
n=511\end{array}$ & $\begin{array}{l}\mathbf{H F} \\
\mathrm{n}=95\end{array}$ & $\mathrm{p}$-value & $\begin{array}{l}\text { Non- } \\
\text { HF } \\
n=491\end{array}$ & $\begin{array}{l}\text { HF } \\
n=129\end{array}$ & p-value & $\begin{array}{l}\text { Non- } \\
\text { HF } \\
\mathrm{n}=428\end{array}$ & $\begin{array}{l}\mathbf{H F} \\
\mathrm{n}=147\end{array}$ & p-value & $\begin{array}{l}\text { Non- } \\
\text { HF } \\
\mathrm{n}=357\end{array}$ & $\begin{array}{l}\mathbf{H F} \\
\mathrm{n}=112\end{array}$ & p-value & $\begin{array}{l}\text { Non- } \\
\text { HF } \\
n=301\end{array}$ & $\begin{array}{l}\text { HF } \\
n=66\end{array}$ & p-value \\
\hline \multicolumn{17}{|l|}{ Processing speed } \\
\hline \multirow[t]{2}{*}{ Perceptual Speed } & $\mathrm{m}$ & 50.1 & 49.2 & 0.613 & 50.1 & 49.6 & 0.753 & 49.8 & 50.7 & 0.490 & 49.9 & 50.2 & 0.818 & 50.1 & 49.3 & 0.970 \\
\hline & $\mathrm{SD}$ & 9.9 & 10.8 & & 10.0 & 10.1 & & 10.2 & 9.4 & & 9.9 & 10.3 & & 9.8 & 11.5 & \\
\hline \multirow[t]{2}{*}{ Symbol-Digit } & $\mathrm{m}$ & 49.7 & 50.2 & 0.869 & 50.1 & 49.5 & 0.624 & 49.9 & 50.4 & 0.666 & 50.0 & 49.8 & 0.886 & 50.2 & 48.5 & 0.483 \\
\hline & $\mathrm{SD}$ & 10.0 & 9.8 & & 9.91 & 10.4 & & 10.0 & 9.9 & & 9.7 & 10.8 & & 10.1 & 9.3 & \\
\hline \multicolumn{17}{|l|}{ Visuospatial ability } \\
\hline \multirow[t]{2}{*}{ BlockDesign } & $\mathrm{m}$ & 50.6 & 45.9 & $<0.001$ & 50.7 & 46.3 & $<0.001$ & 50.8 & 46.6 & $<0.001$ & 50.5 & 47.5 & 0.072 & 50.5 & 46.5 & 0.082 \\
\hline & SD & 10.0 & 9.0 & & 10.1 & 8.7 & & 10.2 & 8.3 & & 10.1 & 8.9 & & 10.1 & 9.0 & \\
\hline \multicolumn{17}{|l|}{ Semantic memory } \\
\hline \multirow[t]{2}{*}{ Verbal Meaning } & $\mathrm{m}$ & 50.0 & 49.7 & 0.787 & 50.0 & 50.1 & 0.883 & 50.2 & 49.5 & 0.595 & 50.6 & 48.3 & 0.122 & 50.1 & 48.6 & 0.531 \\
\hline & SD & 10.0 & 9.9 & & 10.0 & 9.9 & & 10.2 & 9.2 & & 10.0 & 9.8 & & 9.9 & 10.5 & \\
\hline \multirow[t]{2}{*}{ Information Task } & $\mathrm{m}$ & 50.0 & 50.1 & 0.944 & 50.1 & 49.6 & 0.716 & 49.9 & 50.3 & 0.705 & 50.3 & 49.3 & 0.457 & 50.2 & 48.4 & 0.396 \\
\hline & $\mathrm{SD}$ & 10.1 & 9.4 & & 10.0 & 10.1 & & 10.2 & 9.4 & & 10.0 & 9.9 & & 9.8 & 11.1 & \\
\hline \multicolumn{17}{|l|}{ Short term memory } \\
\hline \multirow[t]{2}{*}{ Digit Span-forward } & $\mathrm{m}$ & 50.3 & 47.7 & 0.021 & 50.1 & 49.5 & 0.292 & 50.1 & 49.6 & 0.649 & 49.9 & 50.3 & 0.840 & 49.9 & 50.6 & 0.748 \\
\hline & $\mathrm{SD}$ & 10.0 & 9.6 & & 9.9 & 10.4 & & 9.9 & 10.5 & & 10.3 & 8.5 & & 10.2 & 8.8 & \\
\hline \multirow[t]{2}{*}{ Digit Span-backward } & $\mathrm{m}$ & 50.5 & 46.8 & 0.002 & 50.5 & 47.3 & 0.007 & 50.5 & 48.2 & 0.066 & 50.3 & 48.5 & 0.278 & 50.1 & 49.2 & 0.665 \\
\hline & $\mathrm{SD}$ & 9.9 & 9.6 & & 9.8 & 10.3 & & 10.0 & 9.8 & & 10.0 & 10.0 & & 9.9 & 10.9 & \\
\hline \multicolumn{17}{|l|}{ Episodic memory } \\
\hline \multirow[t]{2}{*}{ Thurstone`s Pictures } & $\mathrm{m}$ & 50.4 & 46.1 & 0.016 & 50.1 & 46.9 & 0.006 & 50.8 & 46.5 & 0.002 & 50.5 & 46.9 & 0.053 & 50.1 & 49.0 & 0.651 \\
\hline & SD & 9.7 & 11.7 & & 9.8 & 10.4 & & 10.0 & 9.4 & & 9.9 & 9.9 & & 10.0 & 10.1 & \\
\hline \multirow[t]{2}{*}{ Prose Recall } & $\mathrm{m}$ & 50.4 & 47.1 & 0.009 & 50.7 & 46.4 & $<0.001$ & 50.8 & 46.6 & 0.002 & 50.4 & 47.8 & 0.180 & 50.0 & 49.5 & 0.852 \\
\hline & SD & 9.9 & 10.3 & & 9.8 & 10.2 & & 10.0 & 9.5 & & 9,9 & 10.2 & & 9.9 & 10.8 & \\
\hline \multirow[t]{2}{*}{ Memory-in-Reality } & $\mathrm{m}$ & 50.4 & 47.1 & 0.009 & 50.4 & 47.5 & 0.016 & 51.0 & 46.1 & $<0.001$ & 50.3 & 48.1 & 0.190 & 50.5 & 48.5 & 0.195 \\
\hline & SD & 9.8 & 10.9 & & 9.9 & 10.2 & & 9.9 & 9.4 & & 9.9 & 10.2 & & 9.9 & 10.2 & \\
\hline
\end{tabular}


Table 4 Parameter estimates of the fixed effect for each cognitive test differences between heart failure (HF) and non-HF population including individuals diagnosed with dementia.

\begin{tabular}{lllllll}
\hline \multirow{2}{*}{ Cognitive tests } & \multicolumn{1}{l}{ Model 1 } & \multicolumn{3}{c}{ Model 2 } & \multicolumn{2}{l}{ Model 3 } \\
\cline { 2 - 6 } & $\begin{array}{l}\text { Mean Level } \\
\text { (SE) }\end{array}$ & Slope (SE) & $\begin{array}{l}\text { Mean Level } \\
\text { (SE) }\end{array}$ & Slope (SE) & $\begin{array}{l}\text { Mean Level } \\
\text { (SE) }\end{array}$ & Slope (SE) \\
\hline Perceptual Speed & $1.63(1.46)$ & $-0.83(0.47)$ & $0.29(1.63)$ & $-0.18(0.53)$ & $0.54(1.64)$ & $-0.23(0.53)$ \\
Symbol-Digit & $0.02(1.41)$ & $-0.20(0.43)$ & $-0.02(1.60)$ & $<0.01(0.48)$ & $-0.01(1.61)$ & $-0.03(0.49)$ \\
BlockDesign & $-2.53(1.26)^{*}$ & $-0.10(0.31)$ & $-2.10(1.49)$ & $-0.19(0.37)$ & $-2.03(1.48)$ & $-0.21(0.37)$ \\
Verbal Meaning & $-1.79(1.33)$ & $-0.64(0.43)$ & $2.07(1.89)$ & $-0.37(0.50)$ & $1.90(1.51)$ & $-0.48(0.47)$ \\
Information Task & $1.63(1.17)$ & $-0.38(0.38)$ & $1.07(1.31)$ & $-0.04(0.43)$ & $1.24(1.31)$ & $-0.08(0.43)$ \\
Digit Span-forward & $1.60(1.33)$ & $-0.71(0.38)$ & $2.54(1.57)$ & $-0.91(0.44)^{*}$ & $2.76(1.57)$ & $-0.94(0.43)^{*}$ \\
Digit Span- & $-1.31(1.37)$ & $-0.09(0.38)$ & $-0.78(1.71)$ & $-0.27(0.49)$ & $-0.61(1.69)$ & $-0.30(0.48)$ \\
backward & & & & & & \\
Thurstone`s & $1.06(1.44)$ & $-0.93(0.37)^{*}$ & $1.01(1.67)$ & $-0.76(0.43)$ & $1.04(1.67)$ & $-0.76(0.43)$ \\
Pictures & & & & & & \\
Prose Recall & $1.69(1.25)$ & $-1.33(0.35)^{*}$ & $2.36(1.47)$ & $-1.39(0.42)^{*}$ & $2.50(1.44)$ & $-1.41(0.42)^{*}$ \\
Memory-in-Reality & $-1.00(1.17)$ & $-0.12(0.30)$ & $-0.67(1.35)$ & $-0.03(0.34)$ & $-0.60(1.34)$ & $-0.04(0.34)$ \\
\hline
\end{tabular}

Model 1 adjusted to intercept, iage, iageq, heartfailure (meanlevel), iage x HF (slope).

Model 2 adjusted for sex, age, educational level and all types of diabetes

Model 3 adjusted for sex, age, educational level, arterial hypertension, diabetes and smoking. $*=p<0.05$. 
Table 5 Parameter estimates of the fixed effect for each cognitive test differences between heart failure (HF) and non-HF population excluding individuals diagnosed with dementia.

\begin{tabular}{|c|c|c|c|c|c|c|}
\hline \multirow[b]{2}{*}{ Cognitive tests } & \multicolumn{2}{|l|}{ Model 1} & \multicolumn{2}{|l|}{ Model 2} & \multicolumn{2}{|l|}{ Model 3} \\
\hline & $\begin{array}{l}\text { Mean Level } \\
\text { (SE) }\end{array}$ & Slope (SE) & $\begin{array}{l}\text { Mean Level } \\
\text { (SE) }\end{array}$ & Slope (SE) & $\begin{array}{l}\text { Mean Level } \\
\text { (SE) }\end{array}$ & Slope (SE) \\
\hline Perceptual Speed & $-0.27(1.84)$ & $-0.26(0.51)$ & - & - & - & - \\
\hline Symbol-Digit & $-0.90(1.72)$ & $0.07(0.52)$ & $-1.87(1.90)$ & $<0.01(0.48)$ & $-1.65(1.89)$ & $0.54(0.56)$ \\
\hline BlockDesign & $-4.88(1.49)^{*}$ & $0.43(0.38)$ & $-4.79(1.69)^{*}$ & $-0.37(0.44)$ & $-4.78(1.70)^{*}$ & $0.37(0.44)$ \\
\hline Verbal Meaning & $1.69(1.90)$ & $-0.83(0.52)$ & $2.04(2.14)$ & $-0.60(0.57)$ & $2.08(2.14)$ & $-0.61(0.57)$ \\
\hline Information Task & $1.98(1.32)$ & $-0.29(0.41)$ & $0.95(2.15)$ & $0.19(0.51)$ & $0.99(2.15)$ & $0.19(0.51)$ \\
\hline $\begin{array}{l}\text { Digit Span- } \\
\text { forward }\end{array}$ & $0.71(1.37)$ & $-0.59(0.36)$ & $1.24(1.61)$ & $-0.78(0.42)$ & $1.30(1.61)$ & $-0.78(0.42)$ \\
\hline $\begin{array}{l}\text { Digit Span- } \\
\text { backward }\end{array}$ & $-2.52(1.53)$ & $0.14(0.41)$ & $-2.41(1.83)$ & $0.14(0.49)$ & $-2.40(1.83)$ & $0.15(0.49)$ \\
\hline Thurstone`s & $-0.71(1.44)$ & $-1.12(0.45)$ & $-0.85(1.57)$ & $-0.31(0.45)^{*}$ & $-1.00(1.57)$ & $-0.29(0.45)$ \\
\hline Pictures & & & & & & \\
\hline Prose Recall & $0.43(1.35)$ & $-0.98(0.40)^{*}$ & $0.96(1.44)$ & $-1.12(0.45)^{*}$ & $1.12(1.44)$ & $-1.15(0.45)^{*}$ \\
\hline $\begin{array}{l}\text { Memory-in- } \\
\text { Reality }\end{array}$ & $-2.27(1.17)$ & $0.34(0.34)$ & $-2.04(1.33)$ & $0.34(0.38)$ & $-2.02(1.33)$ & $0.34(0.38)$ \\
\hline
\end{tabular}

Model 1 adjusted to intercept, iage, iageq, heartfailure (meanlevel), iage x HF(slope).

Model 2 adjusted for sex, age, educational level and diabetes

Model 3 adjusted for sex, age, educational level, arterial hypertension, diabetes and smoking. ${ }^{*}=\mathbf{p}<0.05$;no data 


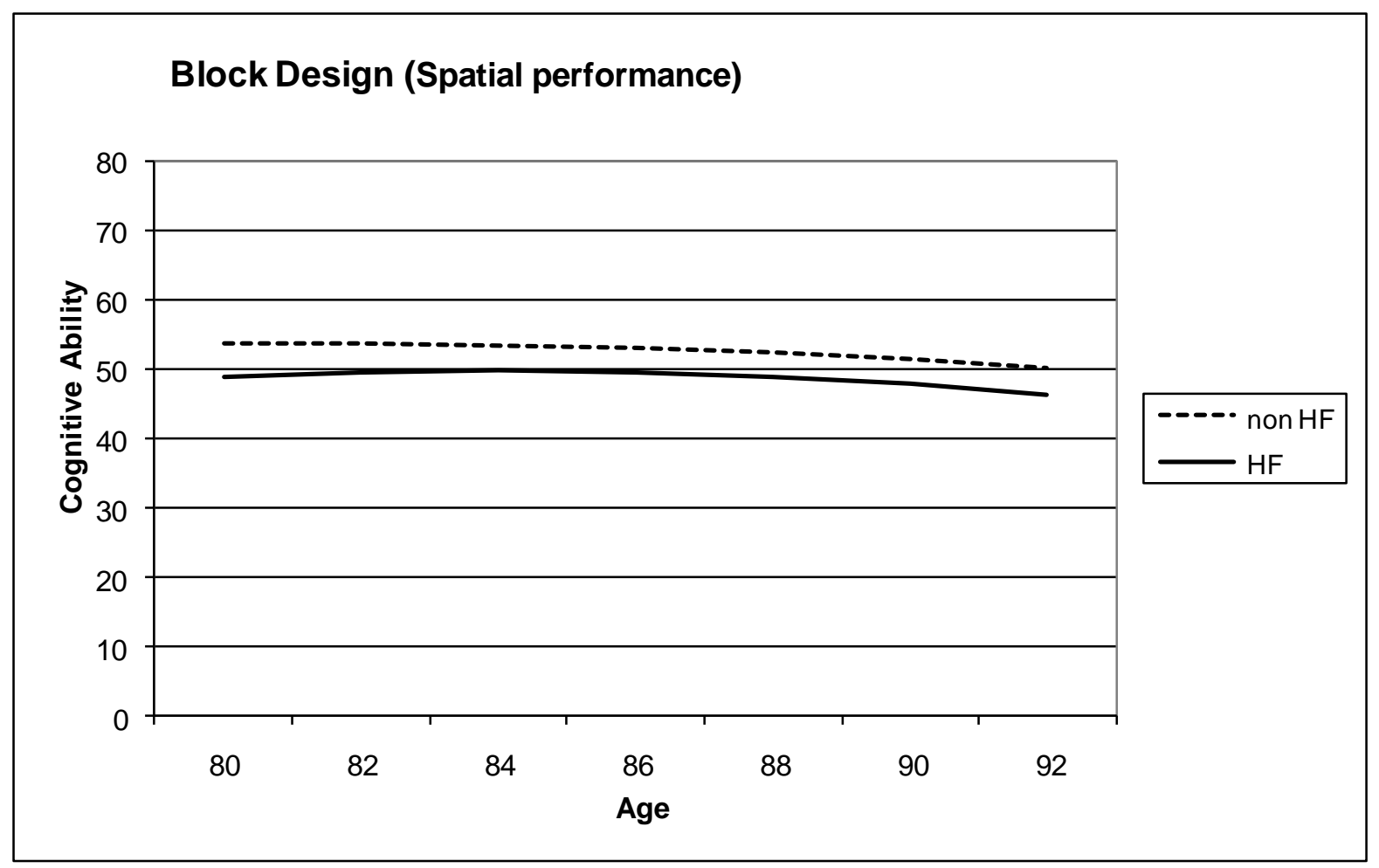

Figure 1. Longitudinal Association between heart failure (HF), non-heart failure (non-HF) and spatial performance. Measured in model 2 (sex, age, educational level, and diabetes) by the first principal component, excluding individuals with dementia. 


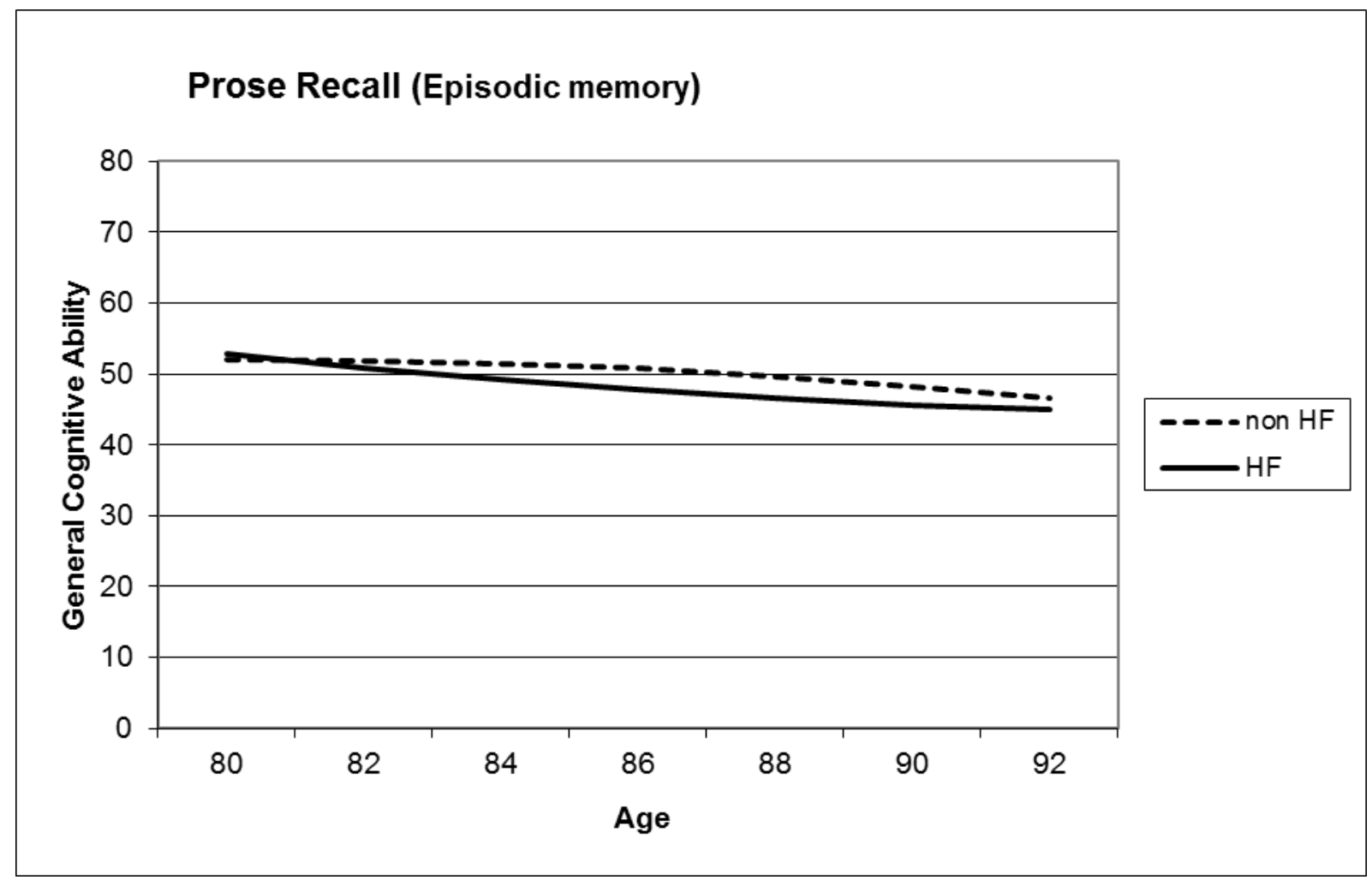

Figure 2. Longitudinal Association between heart failure (HF), non-heart failure (non-HF) and episodic memory. Measured in model 2 (sex, age, educational level, and diabetes) by the first principal component, excluding individuals with dementia. 


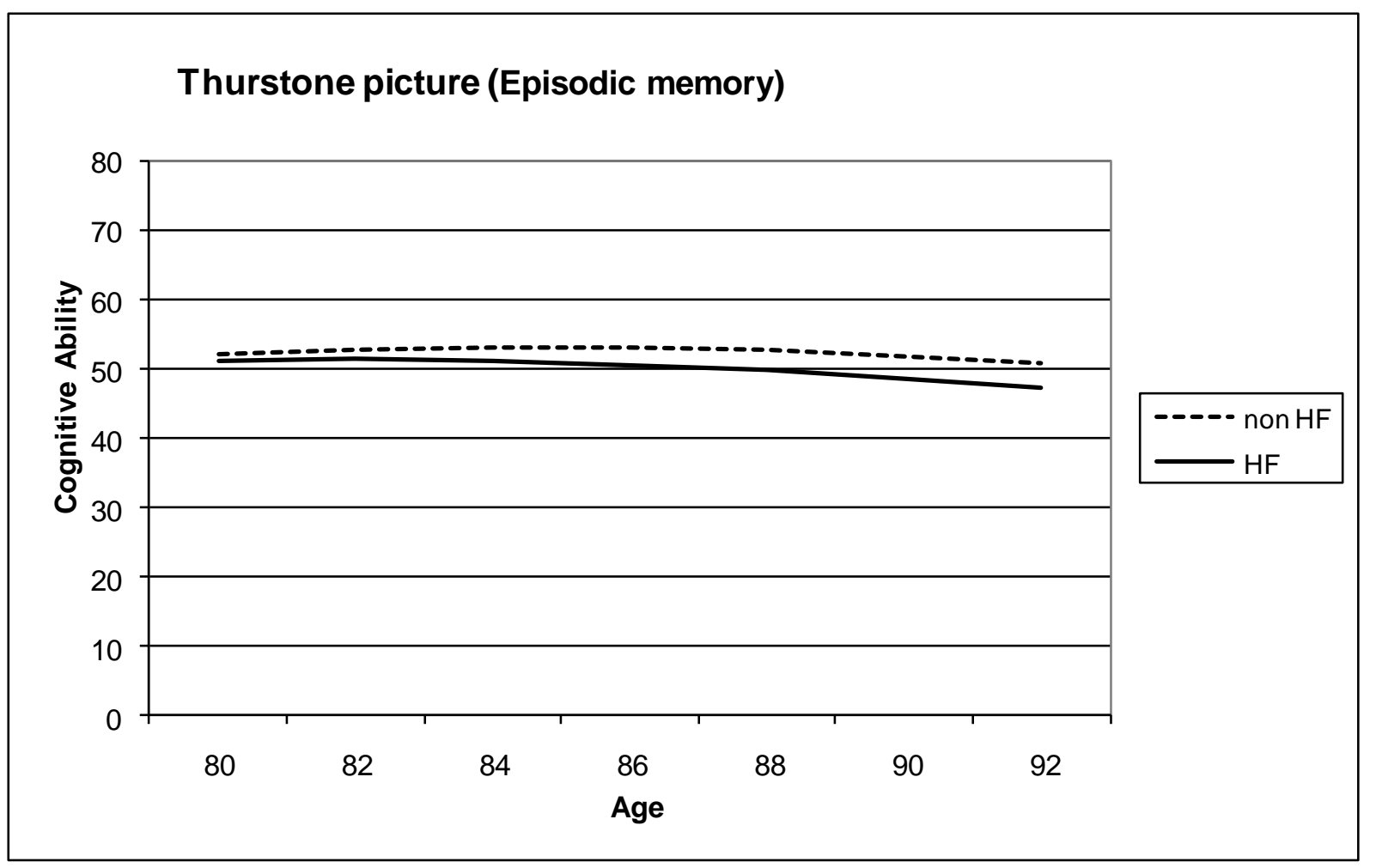

Figure 3. Longitudinal association between heart failure (HF), non-heart failure (non-HF) and episodic memory (Thurstone Picture). Measured in model 2 (sex, age, educational level, and diabetes) by the first principal component, excluding individuals with dementia. 


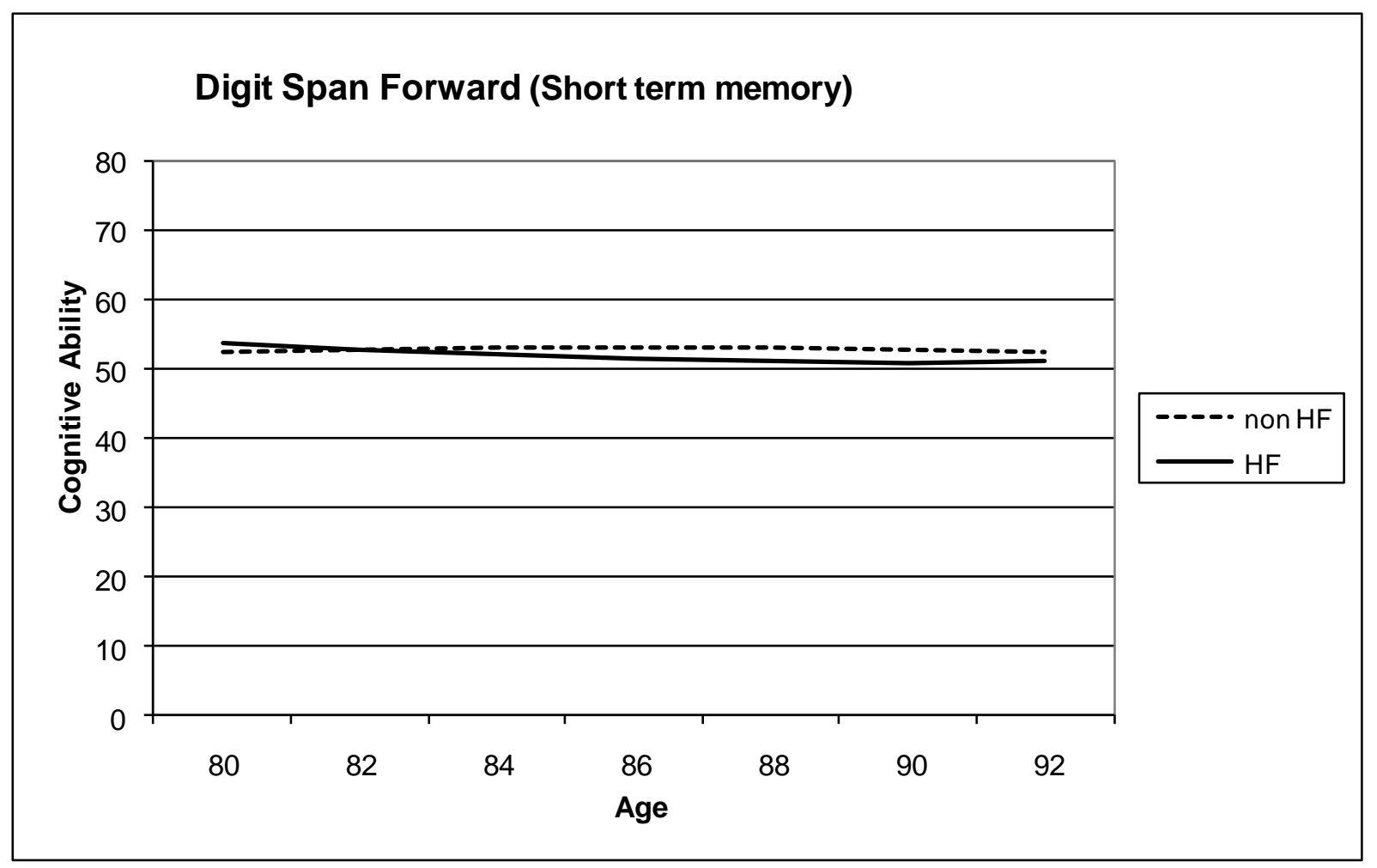

Figure 4. Longitudinal association between heart failure (HF), non-heart failure (non-HF) and short term memory. Measured in model 2 (sex, age, educational level, and diabetes) by the first principal component, including individuals with dementia. 